\title{
LOS MECANISMOS JURÍDICOS DE LUCHA CONTRA LA DISCRIMINACIÓN: APORTACIONES PARA LA CONFIGURACIÓN DEL DERECHO ANTIDISCRIMINATORIO
}

ESTEFANÍA ESPARZA-REYES

FRANCISCO JAVIER DÍAZ REVORIO 
SUMARIO

1. PLANTEAMIENTO: ALGUNOS ASPECTOS SOBRE EL PRINCIPIO DE NO DISCRIMINACIÓN Y EL DERECHO ANTIDISCRIMINATORIO. 2. MECANISMOS DE LUCHA CONTRA LA DISCRIMINACIÓN. 2.1. Aspectos generales y relación con las acciones afirmativas. 2.2. Clasificaciones de los mecanismos de lucha contra la discriminación. 2.2.1. De acuerdo con su finalidad: mecanismos directos y mecanismos indirectos. 2.2.2. De acuerdo con el origen de la disposición que los contiene: mecanismos nacionales o internacionales. 2.2.3. De acuerdo con la jerarquía de la norma que los contiene: mecanismos supraconstitucionales; constitucionales; legales; infralegales, y sin carácter vinculante o privados. 2.2.4. De acuerdo con la especificidad de su protección: mecanismos generales y mecanismos específicos de grupo. 2.2.5. De acuerdo con la forma de protección: mecanismos jurisdiccionales y mecanismos institucionales. 2.2.6. De acuerdo con el grado de protección: eliminación de normas discriminadoras; mandatos de acción y deberes de protección. 3. A MODO DE CONCLUSIÓN 


\title{
LOS MECANISMOS JURÍDICOS DE LUCHA CONTRA LA DISCRIMINACIÓN: APORTACIONES PARA LA CONFIGURACIÓN DEL DERECHO ANTIDISCRIMINATORIO ${ }^{1}$
}

\author{
ESTEFANÍA ESPARZA-REYES \\ Académica Departamento de Ciencias Jurídicas, \\ Universidad de La Frontera (Temuco, Chile) ${ }^{2}$ \\ FRANCISCO JAVIER DÍAZ REVORIO \\ Catedrático de Derecho Constitucional, \\ Universidad de Castilla-La Mancha (Toledo, España)
}

\section{PLANTEAMIENTO: ALGUNOS ASPECTOS SOBRE EL PRINCIPIO DE NO DISCRIMINACIÓN Y EL DERECHO ANTIDISCRIMINATORIO}

Como es bien sabido, la preocupación jurídica por el fenómeno que hoy se conoce como discriminación puede situarse en términos geográficos y cronológicos en la promulgación de la XIV Enmienda de la Constitución de Estados Unidos de Norteamérica y, más específicamente, en la interpretación que de ella hizo la Corte Federal

1 El presente trabajo, se enmarca dentro del proyecto FONDECYT de Iniciación N. ${ }^{\circ} 11170788$ «Configuración de las bases del Derecho Antidiscriminatorio en Chile a través de sus principios jurídicos».

${ }^{2}$ Universidad de La Frontera. Avenida Francisco Salazar 01145. Temuco - Chile. Casilla 54-D. Email: estefania.esparza@ufrontera.cl

3 Facultad C. Jurídicas y Sociales. Universidad de Castilla-La Mancha. Cobertizo de San Pedro Mártir, s/n. 45007 Toledo. Universidad de Castilla-La Mancha. Email: FcoJavier.DRevorio@uclm.es 
de aquel país desde la sentencia «Strauder versus West Virginia» en $1878^{4}$. De igual modo, valga recordar que debido a la historia de esclavitud de tal país, el desarrollo de la no discriminación se realizó, en gran medida, en relación al factor «raza» como primera categoría reconocida a modo de causa de discriminación, categorías que más tarde incluirían el sexo, entre muchas otras.

Desde esta primera interpretación, la lucha contra la discriminación ha experimentado múltiples cambios y un gran desarrollo. De este modo, hablar de discriminación resulta algo habitual en los días que corren y puede señalarse, sin lugar a dudas, que su proscripción es una disposición común en las diversas Constituciones y en los sistemas de protección de derechos humanos, sean estos internacionales o regionales ${ }^{5}$.

La discriminación es en realidad un concepto extra-jurídico, que, sin embargo, adquiere gran importancia y límites distintos para el ordenamiento jurídico. Pero hay más, pues inclusive dentro del Derecho, no existe completo acuerdo en cuanto a la nomenclatura, es así como bajo la definición de discriminación se puede hacer alusión a tres fenómenos, no solo distintos en cuanto a su naturaleza, sino especialmente respecto de su juridicidad.

En el primer grupo se encuentran quienes entienden que la discriminación consiste en cualquier separación o distinción, la que en sí misma no implica ni un criterio por el cual se realice la misma, ni una valoración de índole ética, siendo un concepto neutral y descriptivo ${ }^{6}$, es por este motivo que no es difícil encontrar referencias a «discriminaciones arbitrarias» ${ }^{7}$ o discriminaciones contrarias a la igualdad.

Muy ligado a lo anterior, el segundo grupo, por su parte, entiende también que la discriminación hace alusión a una distinción. Sin embargo, agregándole el adjetivo de «positiva» o «inversa», ésta tiene por finalidad lograr ciertas cuotas de igualdad material o fáctica de las personas que han sufrido tratos vejatorios por el solo hecho de pertenecer a un colectivo determinado, no siendo, en consecuencia, un término neutral.

4 Por otra parte, la preocupación por la igualdad es considerablemente más antigua, puesto que existen antecedentes en la cultura occidental en el pensamiento de Platón y Aristóteles, Rey Martínez (2005). El derecho a no ser discriminado en razón de sexo. México D.F.: Consejo para prevenir la discriminación, p. 20, pero además en el de Heródoto, Heráclito y Anaximandro, Martínez Tapia, Ramón (2000). Igualdad y razonabilidad en la justicia constitucional española. Almería: Universidad de Almería, p. 13, así como en el de Cicerón, Garrido Gómez, María Isabel (2009). La igualdad en el contenido y en la aplicación de la ley. Madrid: Editorial Dykinson, p. 19.

5 Courtis, C. (2008). «Dimensiones conceptuales de la protección legal contra la Discriminación». Revista IIDH del Instituto Interamericano de Derechos Humanos, 48, pp. 157-202, pp. 157 y 158.

6 Rabossi, E. (1990). «Derechos Humanos: El principio de Igualdad y la Discriminación». Revista del Centro de Estudios Constitucionales, 7, pp. 175-192, p. 179.

7 Tal ha sido la forma habitual de tratar la discriminación en Chile, la cual se ha visto consagrada expresamente mediante la ley 20609. Sólo a modo de ejemplo Nogueira Alcalá, H. (2006). «El derecho a la igualdad ante la ley, la no discriminación y acciones positivas». Anuario da Facultade de Dereito da Universidade da Coruña, 10, pp. 799-831, p. 806. 
El tercer grupo resulta bastante amplio en cuanto a su contenido y aglutina varias clases de posturas que entienden la discriminación como una «actitud o acción prejuiciosa» y/o como adopción de un punto de vista carente de razón o injusta, es decir, la realización de una distinción que «no resulta admisible» ${ }^{8}$. Se trata, en consecuencia, de distinciones injustas, sin reparar en la causa de las mismas. En este sentido, para esta postura, una discriminación es un trato diferenciado que carece de una finalidad legítima, idoneidad o proporcionalidad, es decir, que no supera el juicio de igualdad (también llamado de razonabilidad, en cuanto que la distinción sería en tal caso irrazonable), pero también distinciones que se basan en un prejuicio o actitud odiosa frente a las personas que pertenecen a ciertos colectivos.

Con todo, podría entenderse que un trato que no supera el juicio de igualdad o razonabilidad, más que una discriminación propiamente tal sería, en realidad, una vulneración del principio general del Derecho de proscripción de la arbitrariedad que, como se sabe, prohíbe especialmente esta clase de conductas. Sin embargo, ha primado la concepción que sostiene la vulneración de la no discriminación en ambos casos.

Puesto que se estima más razonable la primera postura, puede señalarse que la discriminación, a estos efectos, es ${ }^{9}$ una acción u omisión prejuiciosa ${ }^{10}$ que, utilizando la pertenencia a ciertos colectivos de personas, las trata de manera distinta, debiendo hacerlo de forma igual o, por el contrario, les brinda un tratamiento similar, pese a que los casos son distintos, siendo la desvalorización del otro la causa de este actuar. De esta forma, para que exista discriminación, parece imprescindible que exista un trato odioso basado en la pertenencia a un grupo social o categoría sospechosa ${ }^{11}$.

\footnotetext{
${ }^{8}$ Rabossi, E. (1990). «Derechos Humanos: El principio de Igualdad y la Discriminación». Op. cit., p. 179.

9 En otra ocasión se ha indicado que «la discriminación consiste en brindar un trato igual o distinto basado en el prejuicio que sufren personas pertenecientes a ciertos grupos sociales y que ocasiona, o puede producir una privación del goce de ciertos derechos.», Esparza-Reyes, E. (2018). La igualdad como no subordinación. Un planteamiento de interpretación constitucional. México D.F., Editorial Tirant lo Blanch, p. 36.

${ }^{10}$ Las nociones de estereotipo y de prejuicio resultan fundamentales para la conceptualización de la discriminación y así se ha evidenciado desde la Psicología Social. La primera habría surgido de la imprenta (Rey Martínez, F. (2005). «Igualdad y discriminación: Estrategias contra los estigmas, las castas y la ciudadanía debilitada». En Salazar, O. Y Torres, A. (eds.). La inclusión del otro. Más allá de la tolerancia. Córdoba: Diputación de Córdoba, p. 56) y solo en 1922 a través de los trabajos de Lippman se incorpora al concepto de prejuicio. La idea de prejuicio proveniente de Allport, resulta esencial a la hora de definir los mecanismos por los que surge la discriminación entre los distintos grupos, Ramírez, E.; Estrada, C. E Izerbyt, V. (2016). Estudio correlacional de prejuicio y discriminación implícita y explícita en una muestra magallánica. Revista Atenea, 513, pp. 251-262.

${ }^{11}$ Rey Martínez, Fernando (2017). «Igualdad y prohibición de discriminación: De 1978 a 2018» Revista de Derecho Político, 100, pp. 125-171, p. 128. Coincidentemente con esta idea, se ha señalado que la prohibición de discriminación en sentido estricto, considera la existencia de un grupo social que históricamente ha sido víctima de discriminación, hostilidad o marginación, producto de que sobre sus miembros pesa un prejuicio o valoración social negativa que se basa en estereotipos, VVAA (2012). «Presupuestos de Teoría y Dogmática Constitucional». En Escobar, G. (Dir.). Derechos Sociales y Tutela Antidiscriminatoria. Navarra, Editorial Aranzadi, pp. 287-483, p. 352.
} 
Valga recordar que, si bien en muchos casos se ha entendido que la discriminación solo se produce en casos de trato desigual, resulta mucho más acorde con el espíritu de la protección entender que la discriminación también puede producirse en casos de trato idéntico cuando las situaciones son distintas y, en consecuencia, ocasionan un daño, se trata de la discriminación por indiferenciación ${ }^{12}$.

De este modo, la discriminación por indiferenciación parte de supuestos distintos a la discriminación por trato distinto. En primer lugar, pone énfasis en la actitud fundante de la acción u omisión y en el daño que ocasiona, es decir, en último término entiende de manera completa y amplia la fórmula aristotélica de «tratar igual lo igual y diferente lo que es distinto», pero además ve en el derecho a la igualdad, la obligación no solo, como su nombre indica, de un trato igual, sino como corolario, un trato diverso en casos disímiles, situación que conduce una vez más al mandato de igualdad $^{13}$.

Donde sí parece existir acuerdo es en la intrínseca relación entre el derecho fundamental a la igualdad y la no discriminación, circunstancia que se produce debido a varias razones ${ }^{14}$. A la Historia, pues la proscripción de la discriminación nació de la cláusula de igual protección de Estados Unidos de Norteamérica, que ha sido tradicionalmente entendida como el derecho a la igualdad, siendo parte de la misma. Al contenido del derecho a la igualdad, puesto que, según la mayoría de la doctrina, el derecho fundamental a la igualdad, contendría dos vertientes que en algunos casos pueden encontrarse fundidas: un mandato de trato igual o más exactamente de tratar de manera idéntica ${ }^{15}$, pero al mismo tiempo, contendría lo que se ha reconocido como una prescripción de naturaleza distinta que consiste en no discriminar ${ }^{16}$. Este mandato, seguramente debido a las primeras conductas que se entendieron como discriminatorias, ha sido identificado de manera preferente con no brindar un trato desigual o perjudicial en base a la pertenencia a ciertos colectivos. En este sentido, pese a que se distingue teóricamente ambos mandatos, se tiende a identificar el trato igual con la no discriminación, situación que no resulta del todo adecuada, en virtud de que, des-

12 Cobreros Mendazona, Edorta (2007). «Discriminación por indiferenciación. Estudio y propuesta». Revista Española de Derecho Constitucional, año 27, 81, pp. 71-114.

13 Este argumento ha sido rebatido en múltiples oportunidades, sin embargo pueden encontrarse autores que lo comparten, entre ellos Nogueira Alcalá, H. (2006). «El derecho a la igualdad ante la ley, la no discriminación y acciones positivas». Op. cit., p. 808.

${ }^{14}$ Es necesario no perder de vista que la igualdad se ha consagrado no solamente como derecho subjetivo, fundamental, sino en algunos casos especialmente como valor superior, tal es el caso por ejemplo de España el artículo 1.1 CE así lo establece. Un completo estudio sobre el tema puede consultarse en Díaz Revorio, F. J. (2009). Valores Superiores e Interpretación Constitucional en la Constitución española. Chihuahua, Tribunal Estatal Electoral de Chihuahua.

15 Alexy, R. (2008). Teoría de los Derechos Fundamentales. Traducción de Carlos Bernal Pulido. Madrid, Centro de Estudios Políticos y Constitucionales, pp. 361 y ss.

16 A modo de ejemplo Rodríguez Zepeda, J. (2006). «Una idea teórica de la no discriminación». En De la Torre, C. (Coord.). El derecho a la no discriminación. México D.F., Instituto de Investigaciones Jurídicas, Universidad Nacional Autónoma de México, pp. 29-56, p. 37. 
de el fallo del caso «Yick Wo versus Hopkins» de $1886^{17}$ hasta la actualidad ${ }^{18}$, se ha reconocido la posibilidad de discriminar por otorgar un trato aparentemente neutro que en la práctica perjudica de manera desproporcionada a un colectivo, es la discriminación indirecta, sin olvidar que se ha entendido que igualmente se puede producir discriminación por otorgar un trato igual en casos disímiles (discriminación por indiferenciación). En último término, la proscripción de la arbitrariedad se encuentra unida al derecho a la igualdad por su forma de protección, debido a que en muchas ocasiones en que no se dispone de una norma específica, la igualdad ha servido como protección de la discriminación.

Tal como se ha señalado, la lucha contra la discriminación se ha desarrollado principalmente desde el derecho a la igualdad. Desde esta perspectiva, los constitucionalistas y otros juristas han abordado habitualmente la cuestión como una problemática inserta en el ámbito de la igualdad, sin otorgarle autonomía. Sin embargo, poco a poco se ha creado al efecto una rama con ciertas características autónomas y que se ha designado bajo el nombre de Derecho Antidiscriminatorio. El origen de esta especialidad del Derecho no se encuentra claro. En algunos casos se ha planteado que habría surgido inspirado en el sistema internacional de los Derechos Humanos, a partir de los años setenta en Europa, especialmente mediante la legislación de Gran Bretaña, Países Bajos, Francia, países escandinavos, entre otros $^{19}$, lo cual, unido a los programas de igualdad, habría comenzado a configurar esta rama. Por otra parte, la doctrina mayoritaria ha dejado en evidencia que su nacimiento se habría producido en Estados Unidos de Norteamérica con posterioridad a la Segunda Guerra Mundial ${ }^{20}$.

17118 U.S.356. El caso versaba sobre el desproporcionado impacto sobre la comunidad china que producía el establecimiento de ciertos requisitos a las empresas de lavandería en California. Estos criterios se fueron perfilando mediante distintas sentencias, así se mantuvo en sentencia «Griggs versus Duke Power Company» marzo de 1971 (401 U.S.424.) y sería perfilado definiendo parámetros específicos en «Arlington Heights versus Metropolitan Housing Development Corp.» (429 US 252) de 1970. Con todo, valga mencionar, según ha señalado Carlos Santiago Nino, que en dicho país todavía se discute si estos criterios continúan vigentes, especialmente debido al caso «Bush versus Gore» (531 US 98) de 2000, Nino, E. (2007). «Efecto o intención: Cuál debería ser el requisito en los casos de discriminación». En Alegre, M. y Gargarella, R. (Coords.). El derecho a la igualdad. Aportes para un constitucionalismo igualitario. Buenos Aires, Editorial Lexis Nexis, pp. 227-251, pp. 233 y ss.

18 Salvo en el sistema estadounidense actual, la discriminación indirecta ha tenido gran aceptación en la doctrina y jurisprudencia, solo a modo de ejemplo puede citarse en el sistema europeo la Directiva del Consejo 76/207 CEE de 9 de Febrero de 1976, así como la Directiva 2000/43 CEE de 29 de Junio de 2000 y el en sistema español STC/2004 de 22 de diciembre, aunque el Tribunal Constitucional habría variado en alguna medida el criterio a partir del año 2007. En el sistema interamericano de igual modo se habría reconocido temprana y sostenidamente la existencia de la discriminación indirecta, especialmente desde la OC-18/2003.

19 Añón Roig, M. J. (2001). Igualdad, Diferencias y Desigualdades. México D.F., Editorial Fontamara, p. 59.

${ }^{20}$ Bàrrere Unzueta, M. A. (2014): El Derecho Antidiscriminatorio y sus límites. Lima, Editorial Jurídica Grijley, pp. 29 y 60. 
Con todo, entre la doctrina no parece existir acuerdo sobre los principios que inspirarían este Derecho Antidiscriminatorio, pese a que se han entregado algunos de ellos. A modo de ejemplo, autores han destacado los principios de legalidad; de gravedad social; de simbolismo; de diagnóstico/remedio; de adaptación a situaciones concretas; de especialidad; de contexto social y de protección a las libertades individuales ${ }^{21}$.

La doctrina chilena, por su parte, no ha permanecido ajena a este influjo común, pero al mismo tiempo, presentaría ciertas características distintivas. Así, se ha sostenido que el Derecho Antidiscriminatorio (o Antidiscriminación) se estructuraría en base a tres principios, a saber: un principio epistémico que hace alusión al reconocimiento de que la sociedad posee una estructura social organizada en grupos, algunos de los cuales son vulnerables y desaventajados; un principio igualitario que entiende a dichos grupos como libres e iguales en dignidad y derechos, y un principio interventor que obliga a Estado a emprender acciones positivas para lograr la mayor realización espiritual y material posible de los miembros de estos grupos ${ }^{22}$.

Por otro lado, la doctrina española apenas se ha preocupado, hasta tiempos recientes, de la configuración científica y académica del Derecho Antidiscriminatorio como disciplina autónoma. Como antes se ha apuntado, la mayoría de los autores se han acercado al tema desde la igualdad, con los parámetros propios del Derecho Constitucional o de la Teoría del Derecho, o bien desde el Derecho Administrativo. Aunque existen trabajos muy meritorios, está pendiente el establecimiento de unos fundamentos y perfiles específicos del Derecho Antidiscriminatorio, así como la delimitación de su contenido. Sí existen cada vez más estudios específicos sobre cuestiones o aspectos más concretos, pero sin que se hayan establecido claramente los parámetros comunes de la disciplina.

\section{MECANISMOS DE LUCHA CONTRA LA DISCRIMINACIÓN}

Probablemente la primera tarea del Derecho Antidiscriminatorio, una vez abordado el propio concepto de discriminación, es el estudio, conceptualización y clasificación de los diversos instrumentos conocidos de lucha contra la discriminación. En lo que sigue se abordará un examen, necesariamente limitado, de dichos mecanismos, ensayando algunos criterios de clasificación. Cabe destacar que esta labor, más allá de su incuestionable interés teórico como marco de la disciplina en examen, puede tener innumerables consecuencias prácticas para el posterior examen de concretas normas o medidas adoptadas en un sistema jurídico determinado. A efectos de ejemplificar

${ }^{21}$ Kaufman, G. A. (2010). Dignus inter pares. Un análisis comparado de Derecho Antidiscriminatorio. Buenos Aires, Editorial Abeledo Perrot, pp. 123 y ss.

${ }^{22}$ Muñoz León, F. (2013). «"No a «separados pero iguales” en Chile: Un análisis del Derecho Antidiscriminación chileno a partir de su primera sentencia». Revista de Estudios Constitucionales, 11 (2), pp. 201-227, pp. 203 y 204. 
algunos de los tipos de medidas analizados, se expondrán ejemplos basados en los ordenamientos jurídicos español y chileno, sin pretensiones de exhaustividad ni de llevar a cabo ningún tipo de examen comparado. Se trata simplemente de ejemplificar las distintas tipologías que ensayaremos, con medidas específicas (o, en otros casos, la falta de medidas o la pervivencia de normas discriminatorias) que, por lo demás, son también conocidas en muchos otros países del entorno europeo y americano.

\subsection{Aspectos generales y relación con las acciones afirmativas}

La preocupación por las situaciones de discriminación ha llevado a los Estados y a los distintos sistemas internacionales a adoptar un sinfín de medidas para terminar con ellas. Estas medidas, si bien comparten características similares en cuanto a su finalidad, se presentan bajo distintas formas, métodos y hasta eficacia, se trata de los mecanismos de lucha contra la discriminación.

Los mecanismos de lucha contra la discriminación pueden entenderse como elementos o herramientas, independientemente de su plasmación y destinatarios, mediante los cuales el Estado y en algunos casos, organismos privados, afrontan o pueden afrontar la discriminación.

Es necesario destacar que, de un análisis profundo de estas herramientas, puede indicarse que son muy diversas entre sí, no solamente en la forma en que se plasman, sino que, en varios casos, no parecen inspiradas en los mismos principios. Así, por ejemplo, queda en evidencia, cuando se utiliza un concepto de discriminación que no considera, necesariamente, el elemento de grupo, es decir la pertenencia del afectado a un colectivo históricamente preterido. Esta realidad, unida a su consagración diversa y en distintas épocas, provoca mayor complejidad en el panorama, no solo a la hora de analizar estos mecanismos, sino, especialmente, a la hora de adoptarlos e interpretarlos.

Resulta muy probable que, desde una primera aproximación, tiendan a equipararse estos mecanismos de lucha contra la discriminación con las denominadas acciones afirmativas o medidas de acción positiva. Sin embargo, dicha identificación no sería completamente adecuada, pues según se verá, tales acciones solo consistirían en un mecanismo, aunque el más paradigmático, de lucha contra la discriminación, existiendo muchos más al efecto, es decir, se trata de una relación de género especie.

En un sentido amplio, gran parte de los mecanismos pueden ser calificados de acciones positivas, pues pareciera ser que los autores solo coincidirían plenamente en su finalidad, que es «hacer desaparecer la desigualdad entre los grupos» ${ }^{23}$. Con todo, pueden definirse estas medidas de acción positiva como «todas aquellas medidas, diversas en sus manifestaciones, que tienen como destinatarios directos a per-

${ }^{23}$ Bàrrere Unzueta, M. A. (2003). «Problemas de Derecho Antidiscriminatorio»: Subordinación versus discriminación y acción positiva versus igualdad de oportunidades». Cuadernos electrónicos de Filosofía del Derecho, 9, pp. 1-26, p. 13. 
sonas que están o han estado discriminadas o que se hallan en una situación de desventaja estructural como consecuencia de su pertenencia a un cierto colectivo, pertenencia determinada por la posesión de algún rasgo completamente inmutable e íntimamente ligado, en tanto que definitorio de su identidad, a su dignidad como seres humanos, y que persiguen poner fin a esa situación de desventaja estructural, reducir los niveles de desigualdad entre dichos colectivos (y sus miembros) y el resto de la sociedad, y alcanzar mayores cotas de igualdad real dentro de la comunidad.» ${ }^{24}$.

Estas acciones tienen su antecedente en la India donde, si bien existen medidas de similares características en la década del treinta, las mismas no se constitucionalizaron, sino hasta la Carta Fundamental de 1950, cuando se reservaron puestos en la Administración estatal a una casta tradicionalmente marginada ${ }^{25}$. Sin embargo, lo cierto es que el gran desarrollo provendría de la jurisprudencia de Estados Unidos de Norteamérica, desde la Orden Ejecutiva de 16 de marzo de 1961, la cual ordenaba a las empresas que contratasen con el Gobierno Federal, la adopción de medidas de integración de minorías ${ }^{26}$.

Así, mientras en Estados Unidos de Norteamérica, el desarrollo de estas medidas se basaba en el criterio raza, en la Comunidad Europea, desde los años setenta y ochenta ${ }^{27}$ su despliegue vendría de la mano del género donde, especialmente en materia laboral, comienzan a dictarse directivas, como consecuencia de la Resolución del Consejo de 21 de Enero de 1974, sobre puesta en marcha de un Programa de acción social $^{28}$, que pretenden eliminar la desigualdad a la que se encuentran sometidas las mujeres.

Valga recordar a estos efectos, que durante muchos años se discutió la constitucionalidad de estas medidas, su justificación y fundamento, así como su conveniencia. Sin embargo, desde hace algunos años el problema parece trasladarse hacia sus límites, pues si bien, incluso en la jurisprudencia de la Corte Federal de Estados Unidos de Norteamérica en el año $1987^{29}$ se perfilaron sus contornos, lo cierto es que, especialmente en relación a las actuaciones de privados, continúan existiendo dudas sobre las mismas $^{30}$.

En cualquier caso, es importante destacar que si bien, varios de estos mecanismos pueden ser considerados acciones afirmativas, o incluso supuestos de discriminación inversa (que sería el grado máximo en el que la acción positiva pude provocar un

\footnotetext{
${ }^{24}$ Martín Vida, M. A. (2003). Fundamento y límites constitucionales de las medidas de acción positiva. Madrid, Editorial Civitas, pp. 39 y 40.

${ }^{25}$ Giménez Glück, D. (1999). Una manifestación polémica del principio de igualdad: Acciones positivas moderadas y medidas de discriminación inversa. Valencia, Editorial Tirant lo Blanch, p. 15.

26 Bàrrere Unzueta, M. A. (2014): El Derecho Antidiscriminatorio y sus límites. Op. cit., p. 48.

${ }_{27}$ Giménez Glück, D. (1999). Una manifestación polémica del principio de igualdad...Op. cit., p. 211.

28 Martín Vida, M. A. (2003). Fundamento y límites constitucionales... Op. cit., p. 56.

29480 U.S. 616 «Johnson versus Transportation Agency».

30 Díaz Revorio, F. J. (2015). Discriminación en las relaciones entre particulares. México D.F., Editorial Tirant lo Blanch, p. 130
} 
detrimento o perjuicio a personas concretas no pertenecientes al colectivo minoritario), como por ejemplo el establecimiento de escaños reservados, lo cierto es que algunos de ellos simplemente persiguen poner freno a una discriminación existente, no pudiendo ser calificados, al menos desde una perspectiva tradicional, como acciones positivas o afirmativas. Tal es el caso de disposiciones que establecían la obligatoriedad de una remuneración similar entre hombres y mujeres a igual trabajo o la incorporación de cláusulas de no discriminación ${ }^{31}$. Así, estos mecanismos descritos no pretenden promover a los grupos tradicionalmente excluidos, sino, simplemente, terminar con actos discriminatorios.

Por tanto, los mecanismos de lucha contra la discriminación y las medidas de acción positiva, aunque en un sentido amplio poseen la misma finalidad, presentan importantes diferencias. Así, en un primer sentido, los mecanismos no tienen, exclusivamente, como destinatarios directos a las personas que sufren discriminación, sino que, en muchos casos, sus destinatarios serán, inclusive, quienes la practican, ello con la finalidad de evitar que vuelvan a cometer tales actos. Un ejemplo de esta diferencia está constituido por el establecimiento de agravantes penales de género, tal medida, puede ser considerada un mecanismo de lucha contra la discriminación, más no una acción positiva ${ }^{32}$. Otra diferencia importante es que los mecanismos de lucha contra la discriminación, no necesariamente persiguen lograr más cotas de igualdad real, entendida desde una perspectiva económica, sino solo si esta igualdad real contribuye a la eliminación de la discriminación. Esto queda de manifiesto en el establecimiento de escaños reservados, por ejemplo, con el cual se pretende lograr mayor participación en la toma de decisiones, lo que puede colaborar de manera indirecta con la eliminación de la discriminación.

Conocer y tomar conciencia de la existencia de estos mecanismos, sin lugar a dudas puede entregarnos un panorama general sobre la protección de la discriminación que realiza un país en particular, circunstancia conveniente desde diversas perspectivas: en primer término, pues permite incorporar mecanismos que han resultado

31 Debido a la falta de acuerdo en relación al concepto de acciones afirmativas, existen autores que plantean la posibilidad de que las acciones positivas no se dirijan directamente a las personas afectadas por la discriminación, y en tal sentido, cabría calificar de acciones afirmativas, también, a las medidas generales, pero que causan mayor impacto en los colectivos discriminados, así Dema Moreno, S. (2008). A la igualdad por la desigualdad. La acción positiva como estrategia para combatir la discriminación de las Mujeres. Oviedo, Ediciones KRK, p. 89. Sin embargo, la opinión mayoritaria, parece ser que la finalidad de tales acciones es la búsqueda de mayor igualdad real, o de la igualdad de oportunidades, según la Directiva 76/2007 del Consejo de Ministros de la CEE y no solo la eliminación de la discriminación, siendo ésta una diferencia importante, pues transforma a las primeras en instrumentos mucho más amplios. A modo de ejemplo Fabregat Monfort, G. (2009). Las medidas de acción positiva. La posibilidad de una nueva tutela antidiscriminatoria. Valencia, Editorial Tirant lo Blanch, p. 20.

32 Laurenzo Copello, P. (2006). «Discriminación por razón de género y Derecho Penal». En Cervilla, D. y Fuentes, F. (coords.). Mujer, violencia y Derecho. Cádiz: Universidad de Cádiz-Instituto Andaluz de la Mujer, p. 90 
exitosos en otras latitudes y que no se consideran actualmente en nuestro sistema jurídico. También puede resultar de provecho al visibilizar opciones que, hasta el momento, no se habían considerado como elementos que colaboran o pueden colaborar con la terminación de la discriminación y en último lugar, debido a que una exposición de dichos mecanismos es el comienzo del análisis sobre su adecuación o no a los principios de Derecho Antidiscriminatorio.

\subsection{Clasificaciones de los mecanismos de lucha contra la discriminación ${ }^{33}$}

Tal como se ha señalado, cada país cuenta con múltiples mecanismos de lucha contra la discriminación, por este motivo, el acercamiento a ellos puede resultar complejo, y hasta abrumador, si no se realiza de manera ordenada. En este sentido, una clasificación de estos mecanismos permite comprender de mejor manera las herramientas de las cuales dispone un Estado determinado, pero además colabora en la formación de una idea completa sobre la protección del derecho, ello para evaluar la conveniencia de adoptar otras herramientas, donde puedan resultar subrepresentadas algunas de las categorías que se expondrán.

Los mecanismos de lucha contra la discriminación y los mecanismos de protección de los derechos fundamentales en general, admiten múltiples clasificaciones en base a diversos criterios, de esta manera, cada uno de los mecanismos puede ser examinado y ser parte de distintas categorías, admitiendo ser considerado, por ejemplo, como directo, nacional, legal y cumplir con un mandato de acción, entre otras.

A continuación, se expondrán las múltiples categorías en las que pueden clasificarse los mecanismos de lucha contra la discriminación.

\subsubsection{De acuerdo con su finalidad: mecanismos directos y mecanismos indirectos}

Los Estados han respondido de diversas maneras a la discriminación, así en muchos ordenamientos jurídicos existen disposiciones que, sin proponérselo directamente, han colaborado, colaboran o pueden colaborar con la erradicación de la discriminación. Sin embargo, con el transcurso de los años y seguramente debido al gran influjo que el Derecho Internacional de los Derechos Humanos ejerce en los sistemas nacionales, resulta habitual encontrar en diversos ordenamientos jurídicos normas que proscriben la discriminación y/o que pretenden terminar con la misma, independientemente si responden o no, a los principios de Derecho Antidiscriminatorio.

Es del caso mencionar que todas las disposiciones que consideraremos como mecanismos directos de lucha contra la discriminación, en oposición a los indirectos,

33 Con anterioridad se ha utilizado parte de esta propuesta de clasificación para analizar el Derecho Antidiscriminatorio chileno, Esparza-Reyes, E. (2019). «Algunas reflexiones críticas sobre el derecho a la igualdad como no discriminación en Chile». Cuestiones Constitucionales. Revista Mexicana de Derecho Constitucional, núm. 40, pp. 7-37, p. 21. 
tienen el mismo propósito, pese a que sus procedimientos, jerarquía, origen, técnicas y grado de efectividad varían considerablemente, encontrándose bajo este rótulo diversas medidas que solo comparten su finalidad: terminar con la discriminación que sufren las personas que pertenecen a ciertos grupos por el solo hecho de serlo. Así, los sistemas nacionales, regionales y universal de derechos humanos han optado por uno u otro, o han decidido aplicar más de un mecanismo en su ámbito de competencia. De este modo, los mecanismos directos de lucha contra la discriminación son herramientas jurídicas que tienen por finalidad directa terminar con la discriminación, mientras que los mecanismos indirectos, si bien no se proponen tal finalidad o no han sido creados con la misma, en la práctica, colaboran o pueden coadyuvar con la terminación de la discriminación.

Así, por ejemplo, mientras que mecanismos directos de lucha contra la discriminación son: las cláusulas de no discriminación incorporadas en diversos tratados internacionales; la creación del Instituto de la Mujer en España o el Ministerio de la Mujer y la Equidad de Género en Chile ; la tipificación del delito de odio del artículo 510 del Código Penal español, entre muchos otros, pueden ser considerados mecanismos indirectos: la incorporación del Defensor del Pueblo; la existencia de escaños reservados a las mujeres en el Parlamento, entre otros. Estos dos últimos casos, si bien no tienen por finalidad directa combatir la discriminación, sino otros fines distintos, como velar por los derechos fundamentales de las personas o contribuir a lograr la representación de la mayor cantidad de sectores posibles en un órgano decisorio, respectivamente, pueden colaborar con la erradicación de la discriminación y así ser considerados mecanismos indirectos.

Como puede notarse, esta clasificación es de suma importancia, pues precisamente el conocimiento de los mecanismos indirectos puede entregarnos algunas opciones novedosas a la hora de buscar nuevas vías de protección, es decir, se trata de exponer otras vías, casi siempre establecidas para la protección de los derechos fundamentales en general, y así lograr que la protección contra la discriminación sea mayor.

\subsubsection{De acuerdo al origen de la disposición que los contiene: mecanismos nacionales o internacionales}

No se hace alusión en este apartado a si la herramienta en particular resulta o no aplicable en un país determinado, sino al origen de la disposición. Así, serán muchos los mecanismos que estén consagrados en otros países y no resulten aplicables en el nuestro y de igual manera, de trascendental importancia, mecanismos consagrados en los sistemas regionales o universal de derechos humanos que pueden resultar aplicables en un país determinado.

En este sentido, los tratados internacionales y las Constituciones o leyes de otras naciones que combatan la discriminación, siempre serán considerados mecanismos externos mientras que las leyes, decretos y Constitución propia, serán considerados nacionales. 
2.2.3. De acuerdo con la jerarquía de la norma que los contiene: mecanismos supraconstitucionales; constitucionales; legales; infralegales, y sin carácter vinculante o privados

Como su nombre indica, esta clasificación hace alusión a la jerarquía del soporte de la disposición que consagra un determinado mecanismo.

Todos y cada uno de estos mecanismos pueden estar contenidos en normas de diversas categorías y especialización, de este modo, existen, por ejemplo, tratados generales que abordan de manera tangencial la discriminación, así como otros específicos, que se ocupan del tema y, todavía otros, referidos únicamente a la discriminación que sufre algún grupo social determinado. Estas herramientas pueden encontrarse no solamente en pactos internacionales, sino, en algunos casos, también en Constituciones, en directivas, leyes, decretos y hasta normas particulares. En estos últimos casos, una vez más los países han utilizado distintas formas en su plasmación: en algunos casos se han dictado leyes o programas especiales generales, que recogen distintos mecanismos de protección de la discriminación, mientras que, en otras ocasiones, se han dictado normas específicas para algún grupo determinado, se trata solamente del lugar donde se plasman, dependiendo su efectividad de un sinfín de factores, especialmente de las formas de control que establezcan.

Desde una perspectiva tradicional, puede estimarse que los mecanismos de lucha contra la discriminación solamente se encuentran en leyes, pues ella es la manera más clásica y evidente de incorporar estas herramientas, prueba de esto son las leyes de igualdad en su amplia variedad. Sin embargo, como consecuencia del efecto irradiación reconocido a los derechos fundamentales, un análisis más detenido puede dar cuenta que los mismos están presentes también en normas supralegales, entendidas como disposiciones que emanando de organismos internacionales, al versar sobre derechos fundamentales, poseerían un rango supra o, a lo menos, constitucional. De igual forma, las mismas cartas fundamentales, en muchas ocasiones, consagran herramientas que colaboran con la eliminación de la discriminación, piénsese a estos efectos en las cláusulas de no discriminación. Pero ello no es todo, porque también encontramos mecanismos en decretos y normativa propia de la Administración estatal, tales como programas de acción de órganos estatales.

El caso más interesante, a estos efectos, parece ser el de medidas que no poseen jerarquía normativa y que, sin embargo, se adoptan en determinados contextos. Estos mecanismos pueden ser calificados de privados, pues de manera voluntaria, particulares deciden emprender acciones, las cuales tienen como finalidad o resultado, terminar con la discriminación. Si bien pudiera pensarse que estas medidas no son frecuentes, en la práctica, muchas instituciones deciden instaurarlas, piénsese en el establecimiento de cuotas reservadas especialmente para mujeres en algunas empresas, por ejemplo. 


\subsubsection{De acuerdo con la especificidad de su protección: mecanismos generales y mecanismos específicos de grupo}

Si bien la protección de la discriminación comprende a todos los seres humanos, la especial situación en la que se encuentran ciertas personas por su sola pertenencia a un colectivo determinado ha generado, además de su individualización, la creación de mecanismos específicos que abordan, de manera exclusiva, la realidad de quienes componen dichos grupos sociales ${ }^{34}$.

Por lo anterior, es posible distinguir mecanismos que prohíben la discriminación en general, es decir a todos los seres humanos, tales como las cláusulas de no discriminación contenidas en tratados internacionales generales, como por ejemplo el artículo 7 de la Declaración Universal de derechos Humanos de $1945^{35}$ o el artículo 14 de la Constitución española de $1978^{36}$ y los mecanismos que prohíben discriminar a un grupo determinado de manera específica, tal es el caso de la Convención sobre la eliminación de todas las formas de discriminación contra la mujer de 1979 ${ }^{37}$ o la Convención Internacional sobre la Eliminación de todas las Formas de Discriminación Racial de $1965^{38}$.

${ }^{34}$ Se sigue en este punto la definición de grupo social de Iris Marion Young, para quien «un grupo social es un colectivo de personas que se diferencia al menos de otro grupo a través de formas culturales, prácticas o modos de vida. ",Young, I. M. (2000). La Justicia y la política de la diferencia. Traducción de Silvina Álvarez Medina. Madrid, Ediciones Cátedra, p. 77. En cualquier caso, pareciera todavía más específico entender que un grupo social es «un conjunto de personas, cuyo tamaño puede variar considerablemente, las cuales se encuentran ligadas desde la perspectiva de la identidad en un sentido interno, en cuanto sus propios miembros se identifican con él y en un sentido externo, en razón de que son percibidos por otros como pertenecientes a dicho grupo.», Esparza-Reyes, E. (2018). La igualdad como no subordinación... Op. cit., p. 65.

35 Artículo 7 DUDH: «Todos son iguales ante la ley y tienen, sin distinción, derecho a igual protección de la ley. Todos tienen derecho a igual protección contra toda discriminación que infrinja esta Declaración y contra toda provocación a tal discriminación.».

36 Artículo 14 CE: «Los españoles son iguales ante la ley, sin que pueda prevalecer discriminación alguna por razón de nacimiento, raza, sexo, religión, opinión o cualquier otra condición o circunstancia personal o social.».

37 Artículo 2 CEDAW: «Los Estados Partes condenan la discriminación contra la mujer en todas sus formas, convienen en seguir, por todos los medios apropiados y sin dilaciones, una política encaminada a eliminar la discriminación contra la mujer...», mientras que el artículo 1 prescribe: «A los efectos de la presente Convención, la expresión «discriminación contra la mujer» denotará toda distinción, exclusión a restricción basada en el sexo que tenga por objeto o por resultado menoscabar o anular el reconocimiento, goce o ejercicio por la mujer, independientemente de su estado civil, sobre la base de la igualdad del hombre y la mujer, de los derechos humanos y las libertades fundamentales en las esferas política, económica, social, cultural y civil o en cualquier otra esfera.».

38 Artículo 2 ICERD: «1. Los Estados partes condenan la discriminación racial y se comprometen a seguir, por todos los medios apropiados y sin dilaciones, una política encaminada a eliminar la discriminación racial en todas sus formas y a promover el entendimiento entre todas las razas...» y su artículo 1 señala: «1. En la presente Convención la expresión «discriminación racial» denotará toda distinción, exclusión, restricción o preferencia basada en motivos de raza, color, linaje u origen nacional o étnico que tenga por objeto o por resultado anular o menoscabar el reconocimiento, goce o ejercicio, en condiciones de igualdad, de los derechos humanos y libertades fundamentales en las esferas política, económica, social, cultural o en cualquier otra esfera de la vida pública.». 
Es necesario destacar que, en este punto, no se hace alusión al carácter o la dimensión estructural abierta o restringida de la no discriminación, entendida como campo o materia específica en que resultaría aplicable una norma ${ }^{39}$, sino a la amplitud de la protección en relación con grupos específicos de manera exclusiva y excluyente o de modo general sin distinción.

\subsubsection{De acuerdo con la forma de protección: mecanismos jurisdiccionales y mecanismos institucionales}

Seguramente por una especie de «deformación profesional», a la hora de preguntarse por la protección de los derechos, en este caso la protección contra la discriminación, suelen visualizarse rápida y casi únicamente procedimientos jurisdiccionales, sin embargo, desde la perspectiva del Derecho Antidiscriminatorio, en ningún caso es la única opción de protección disponible.

Tal como ha ocurrido con todos los criterios de clasificación anteriores, estos procedimientos igualmente son susceptibles de subcategorizaciones y de este modo, nos encontramos que los mismos pueden referirse de manera específica a casos de discriminación, distinguiendo o no en relación con los diversos grupos sociales, o por el contrario, puede tratarse de procesos establecidos de manera general para varios tipos de vulneraciones a los derechos fundamentales, los que, a su vez, pueden ser generales o sectoriales, es decir, referidos a todos los ámbitos de la vida o a alguno en especial.

Estos procedimientos judiciales son de la mayor importancia, pues suelen entregar protección en situaciones concretas de vulneración, piénsese a estos efectos, y en relación a Chile, en el proceso judicial establecido en el artículo 57 de la Ley 20.422 que establece normas sobre igualdad de oportunidades e inclusión social de personas con discapacidad de 10 de febrero de 2010, el procedimiento consagrado en el artículo 3 de la Ley 20.609 que establece medidas contra la discriminación de 24 de julio de 2012 o la Acción de Protección consagrada en el artículo 20 de la Constitución Política de la República.

Con todo, como se indicó, los procedimientos judiciales están lejos de ser la única forma en que los Estados responden a la discriminación. Reconocer y relevar la existencia de otra clase de medidas cuya finalidad consiste, igualmente, en proteger de la discriminación, sin que medie, en principio, intervención judicial, resulta de la mayor utilidad, se trata de los mecanismos institucionales de lucha contra la discriminación.

Esta subcategoría agrupa a un sinfín de medidas de la más variada índole. Sin embargo, pese a lo que pueda creerse, no solamente hace referencia a órganos creados

39 Bayefsky, A. (2005). «El principio de igualdad y no discriminación en el Derecho Internacional» en VVAA. 18 Ensayos de Justicia Transicional, Estado de Derecho y Democracia. Santiago de Chile, Centro de Derechos Humanos, pp. 1-33, pp. 5 y 6. 
al efecto, así, el Instituto de la Mujer o el Defensor del Pueblo en España, sino también a una gran cantidad de acciones, como la existencia de cláusulas de no discriminación; el establecimiento de cuotas reservadas o la obligación de la elaboración de un informe de impacto de género de los proyectos de ley, establecido en la Ley 30/2003, de 13 de Octubre, sobre medidas para incorporar el impacto de género en las disposiciones normativas que elabore el Gobierno.

\subsubsection{De acuerdo con el grado de protección: eliminación de normas} discriminadoras; mandatos de acción y deberes de protección

En la presente clasificación se hace alusión a distintos niveles o bandas de protección de acuerdo con su intensidad, es decir, los mecanismos se organizan desde la menor a la menor intensidad de la protección.

En el primer nivel, a modo de protección básica, se encuentra la eliminación de las disposiciones discriminadoras dentro de un determinado ordenamiento jurídico. Esta normativa, puede discriminar directa o indirectamente, es decir, puede excluir o dar un trato de privilegio de manera expresa en el texto, o producir discriminación en la práctica.

Es posible afirmar que todas las legislaciones, en distintas medidas, poseen o han poseído disposiciones que de manera directa o indirecta, discriminan a ciertos colectivos. El cambio que se ha producido en la calificación de tales normas, es decir, en considerarlas discriminatorias, obedece a un sinnúmero de motivos, pero valga mencionar aquí tres aspectos de la mayor trascendencia: el primero de ellos es la ratificación de tratados internacionales que proscriben la discriminación en los distintos países, hecho que, sin lugar a dudas, ha uniformado enormemente la convicción de que la discriminación es una realidad perniciosa, e incentivado a los Estados a eliminar las disposiciones que puedan considerarse como discriminatorias. El segundo factor, es que producto de los cambios que han experimentado las sociedades, la normativa deja de reflejar los valores o las creencias de la población, en este sentido, puede afirmarse que en la eliminación de las normas discriminatorias ha influido también que ellas ya no resultan útiles para la sociedad, y por el contrario, pueden ser contrarias a los actuales estilos de vida. Como tercer motivo y con distinto grado de desarrollo en relación con el grupo discriminado que afecte, puede mencionarse la presión que realizan los grupos organizados de defensa de los derechos de las «minorías», tales como grupos de mujeres feministas o LGTB.

La eliminación de disposiciones discriminatorias, puede llevarse a cabo de manera expresa o tácita, es decir, mediante un proceso formal de modificación, derogación, o a través de un cambio en la interpretación de un determinado precepto o su no utilización. Lo relevante, para estos efectos, será que las disposiciones discriminatorias dejen de ser utilizadas.

Desde una perspectiva histórica podemos encontrar múltiples ejemplos, así en España, sólo fue mediante la Real Orden firmada el 8 de marzo de 1910 por Álvaro 
de Figueroa y Torres que se terminó con la exclusión histórica de las mujeres en las Universidades $^{40}$; la eliminación de los «actos homosexuales» de la Ley 16/1970, sobre peligrosidad y rehabilitación social de 6 de agosto de $1970^{41}$, que se llevó a efecto en el año 1979 o la derogación del Código de Justicia Militar, mediante la Ley Orgánica 13/1985 de 9 diciembre, que en su artículo 352 tipificaba los «actos deshonestos con individuos del mismo sexo» ${ }^{42}$. Los ejemplos son múltiples y referidos a distintos ámbitos de la vida privada y pública. El caso chileno es relativamente similar, pues en el año 1999 mediante la Ley 19.617 que modifica el Código Penal, el Código de Procedimiento Penal y otros cuerpos legales en materias relativas al delito de violación, se eliminó el delito de sodomía establecido en el artículo 365 del primer cuerpo normativo $^{43}$.

En este sentido, valga mencionar que, pese a lo poco ambiciosas de estas medidas, particularmente en Chile, continúan existiendo dos disposiciones emblemáticas como normas que vulneran el derecho a no ser discriminado, se trata de la redacción actual del mismo artículo 365 del Código Penal, que castiga las relaciones sexuales consentidas entre personas del mismo sexo, cuando una de ellas es menor de edad ${ }^{44}$ y el artículo 1749 del Código Civil, que establece que el marido es el jefe de la sociedad conyugal, sin posibilidad de mudar tal situación ${ }^{45}$, ello pese a las múltiples recomendaciones de organismos internacionales de modificar este aspecto.

40 Ricoy Casas, M. A. (2010). ¿Qué es igualdad. El principio de igualdad formal y no discriminación por razón de sexo en el ordenamiento jurídico español. Madrid, Editorial Dykinson, p. 285.

41 Platero, R. (2011). «La discriminación por orientación sexual e identidad de género». En Álvarez Conde, E. et al. (Dir.). Estudios Interdisciplinares sobre Igualdad. Madrid, Editorial Iustel, pp. 195-208, p. 196.

42 Art. 352 Código de Justicia Militar «El que cometa actos deshonestos con individuos del mismo sexo, será castigado con la pena de seis meses y un día a seis años de prisión militar. Cualquiera que sea la pena impuesta por este delito, llevará siempre consigo la separación del servicio.» (derogado)

43 Artículo 365 Código Penal: «El procesado por el delito de sodomía sufrirá la pena de presidio menor en su grado medio.

Se impondrá la pena de presidio menor en su grado máximo a presidio mayor en su grado medio al que cometiere el delito concurriendo algunas de las siguientes circunstancias:

1. Cuando se use de fuerza o intimidación sobre la víctima, y

2. Cuando se halle la víctima privada de razón o de sentido por cualquier causa.

3. Se impondrá la pena de presidio mayor en su grado medio a máximo si el ofendido fuere menor de catorce años cumplidos, aun cuando no concurra ninguna de las circunstancias expresadas en los dos números del inciso anterior.» (derogado)

44 Artículo 365 Código Penal: «El que accediere carnalmente a un menor de dieciocho años de su mismo sexo, sin que medien las circunstancias de los delitos de violación o estupro, será penado con reclusión menor en sus grados mínimo a medio.»

45 Artículo 1749 Código Civil: «El marido es jefe de la sociedad conyugal, y como tal administra los bienes sociales y los de su mujer; sujeto, empero, a las obligaciones y limitaciones que por el presente Título se le imponen y a las que haya contraído por las capitulaciones matrimoniales.

Como administrador de la sociedad conyugal, el marido ejercerá los derechos de la mujer que siendo socia de una sociedad civil o comercial se casare, sin perjuicio de lo dispuesto en el artículo $150 \ldots$... 
Por otra parte, como es sabido, actualmente prima la concepción que entiende los derechos fundamentales como normas objetivas de principio, esto quiere decir que tales derechos, entre ellos a no ser discriminado/a, crean para el Estado, y en ocasiones para los particulares, obligaciones que van más allá de la mera abstención. En otras palabras, se supera la concepción originaria consistente en que solo el Estado puede vulnerar los derechos fundamentales y en la cual, los derechos operan exclusivamente como límites o prerrogativas de sus titulares ${ }^{46}$, pero además, y de la mayor importancia, se establece que los poderes estatales no solo deben conformarse con no vulnerar directamente los derechos, sino que, por el contrario, deben asumir un rol preponderante en su promoción y protección.

Entender los derechos fundamentales como normas objetivas de principio y decisiones axiológicas ${ }^{47}$, supone que los primeros crean obligaciones estatales. Böckenför$\mathrm{de}^{48}$ ha clasificado estas obligaciones en mandatos de acción y deberes de protección, de esta forma, siguiendo la nomenclatura, pero incorporando nuevos elementos, es posible afirmar que existen mecanismos que dan cumplimiento tanto a los mandatos de acción, cuanto a los deberes de protección.

Los mandatos de acción, desde una perspectiva general, puede indicarse que intentan promover los derechos. Vistos como mecanismos de lucha contra la discriminación, consisten en acciones estatales, pero que en ocasiones pueden ejecutar los privados, que tienen por finalidad, prevenir, promover o desarrollar el derecho a no ser discriminado. En este caso no se aborda una vulneración concreta del derecho a no ser discriminado, sino que, se intenta prevenir, en términos generales, que ella ocurra. Ejemplos de esta clase de mecanismos, están constituidos por la existencia de cláusulas de no discriminación en los tratados internacionales, Constituciones o leyes; el desarrollo de planes de igualdad en las empresas, establecidos en el artículo 45 de la Ley Orgánica 3/2007 de 22 de Marzo, para la igualdad efectiva entre mujeres y hombres o las campañas de sensibilización, contra distintas formas de discriminación como el racismo, llevadas a cabo por particulares o por organismos públicos. En un sentido similar, y especialmente, en relación con los mecanismos indirectos de protección, es dable afirmar que serían mandatos de acción, el establecimiento de escaños reservados en el Parlamento o algunas garantías en relación a la preferencia de personas pertenecientes a colectivos discriminados, si se encuentran en igualdad de condiciones, piénsese a estos efectos en becas o puestos de trabajo. De este modo, particularmente en estos mandatos de acción, cuando se trata de mecanismos indirectos, es posible encontrar distintas intensidades, desde acciones no susceptibles de afectar los derechos de terceros, hasta mecanismos que efectivamente pueden producir una merma en los

46 Anzures Gurría, J. J. (2010). «La eficacia horizontal de los derechos fundamentales». Revista Cuestiones Constitucionales. Revista Mexicana de Derecho Constitucional, 22, pp. 3-51, p.12.

47 Böckenförde, E. W. (1993). Escritos sobre Derechos Fundamentales. Baden-Baden, Nomos Verlagsgesellschaft, p. 95.

48 Böckenförde, E. W. (1993). Escritos sobre Derechos Fundamentales. Op. cit., p. 114. 
derechos de otras personas que no se encuentran directamente implicados en la situación de discriminación.

Los deberes de protección, por su parte, hacen alusión a obligaciones estatales que intentan poner fin a vulneraciones directas, constituyen respuestas de los poderes estatales a violaciones concretas o a lo menos, a amenazas de vulneraciones particulares. Estos deberes de protección tienen dos diferencias importantes con los mandatos de acción, la primera de ellas que ya fue señalada, es que tiene por finalidad evitar una discriminación concreta o poner fin a la misma protegiendo a quien se vea afectado, mientras que en los mandatos de acción no existe un afectado/a en particular. La segunda diferencia importante, es el grado de afectación en el caso de los mecanismos directos, puesto que, sin lugar a dudas, en los deberes de acción, es posible afectar los derechos de la persona que ha ejercido discriminación, mientras que los mandatos de acción, considerados mecanismos directos, al no existir vulneración concreta, no son susceptibles de afectar, a priori, los derechos de particulares.

El ejemplo paradigmático de estos deberes de protección, está constituido por el establecimiento de procedimientos judiciales que tienen por finalidad frenar la discriminación y/o asegurar la debida protección del afectado/a, así la sanción establecida en los artículos 511 y 512 del Código Penal. Igualmente, desde una óptica general, el procedimiento de tutela de derechos fundamentales, establecido en el artículo 53.2 CE, puede ser considerado una manifestación de estos deberes de protección.

Es del caso mencionar que, también es posible hallar estos deberes de protección en ámbitos diversos, sin que se trate de procedimientos judiciales propiamente tales, se trata de la posibilidad de adoptar medidas como separación de espacios físicos en casos de discriminación, por parte de los empleadores o encargados de un establecimiento educacional

\section{A MODO DE CONCLUSIÓN}

Si bien es posible afirmar la existencia de un número considerable de preceptos que pretenden poner fin a la discriminación, o que al menos pueden coadyuvar a terminar con dicho fenómeno (mecanismos directos e indirectos respectivamente), desde una primera aproximación no resulta plausible aseverar que todos ellos posean elementos comunes o deriven de una raíz común, puesto que existen patentes diferencias en la forma en que estos fueron consagrados, en el tiempo en que fueron adoptados e, inclusive, en la manera de entender o conceptualizar la discriminación.

Como puede notarse, los mecanismos que prestan una mayor utilidad son los mecanismos directos de lucha contra la discriminación, sin embargo conocer los indirectos presta enorme utilidad, ello desde diversas perspectivas, a saber: permite conocer el panorama general de un Estado en materia de protección del derecho a no ser discriminado y visibiliza herramientas que colaboran en la terminación de la dis- 
criminación, entregando mayores posibilidades de protección a las personas, por cuanto disponen de más mecanismos al efecto.

La identificación de los mecanismos de lucha contra la discriminación, tiene sendas ventajas, así por ejemplo, contribuye con el inicio del análisis en relación a los principios que deben inspirar el Derecho Antidiscriminatorio, en otras palabras, este conocimiento permite evaluar de manera más clara, cuáles son los principios fundantes de esta nueva rama del Derecho. En este sentido, es importante destacar que permite orientar políticas públicas en materia de no discriminación, dado que es posible identificar con mayor claridad y precisión, y de acuerdo a la clasificación expuesta, qué clase de mecanismos deben crearse o cuáles de ellos no resultan efectivos en un contexto dado.

Ahora bien, producto de múltiples factores, entre los que cabe mencionar la crisis del Estado liberal y el surgimiento del Estado social de Derecho que creó obligaciones concretas para los Estados; el cambio en la estructura de los derechos fundamentales como normas objetivas de principio, que obligan a los particulares a no vulnerar y al Estado a emprender acciones tendientes al desarrollo, promoción y protección de los derechos, así como los fenómenos de discriminación estructural que sufren muchas personas, los Estados se enfrentan a nuevos desafíos.

Estos desafíos no admiten que la respuesta estatal sea simplemente el establecimiento de procedimientos judiciales, es decir, mecanismos judiciales, sino especialmente, el desarrollo de mecanismos institucionales de lucha contra la discriminación. En consecuencia, estos mecanismos no son solo útiles y, eventualmente, parte del Derecho Antidiscriminatorio, sino una herramienta eficaz a la hora de enfrentar este pernicioso fenómeno. Así, es posible afirmar que, inclusive dentro de los procedimientos ante la judicatura, conviene su utilización, en los casos en que una condena, no satisface a la víctima o no termina con discriminaciones de larga data.

Solo conociendo y tomando decisiones acertadas en relación con esta clase de mecanismos, será posible transitar hacia un mundo en que no haya lugar para la discriminación.

Title:

Anti-discriminatory legal mechanisms. Contributions for the Anti-discriminatory Law configuration.

\section{Summary:}

1. Brief aspect about non discrimination principle. 2. Anti-discriminatory legal mechanisms. 2.1. General aspects and their relationship with the 
affirmative action. 2.2. Anti-discriminatory legal mechanisms classification. 2.2.1. According to purpose: Direct and Indirect Mechasnisms. 2.2.2. According to legal norm containing them: National and International Mechanisms. 2.2.3. According to hierachy of the legal norma containing them: Supraconstitutional; Constitutional; Legal; Infralegal and Non binding or Privates Mechanisms. 2.2.4. According to specificity protection: General and Groups Mechanisms. 2.2.5. According to protection way: Judicial and Institutional Mechanisms. 2.2.6. According to Protection: elimination of discriminatory norms; mandates of action duties of protection. 3. Conclusión.

\section{Resumen:}

Desde hace algunos años, ha tomado fuerza la existencia de una rama específica del Derecho denominada Derecho Antidiscriminatorio. Sin embargo, no existe un tratamiento sistemático de tal disciplina, por lo cual se requiere de un análisis acabado de sus postulados centrales, así como de los mecanismos de los que se vale para enfrentar el fenómeno de la discriminación.

Los Estados, en ocasiones inspirándose en la regulación internacional sobre la materia, han utilizado diversas herramientas para combatir la discriminación con mayor o menor éxito, aunque en ocasiones tales medidas no se visualizan como formas de protección. Con todo, los mecanismos de lucha contra la discriminación suelen compartir rasgos comunes que hace plausible sistematizarlos bajo categorías de análisis válidas para diversos ordenamientos jurídicos.

Solo analizando estos mecanismos mediante categorías, será posible formarse una idea cabal del estado del Derecho Antidiscriminatorio en un sistema jurídico dado y, de esta forma, contribuir a su desarrollo.

\footnotetext{
Abstract:

For some years, the existence of a specific Law called Anti-discriminatory Law took force. However, there is not a systematic treatment of such discipline, so is needed a comprehensive analysis of their central postulates and mechanisms to fight discrimination.

The states sometimes inspired by international regulation on the subject have used various tools to combat discrimination with greateror lesser success although sometimes these measures are not visualized as forms of protection.

However, the non-discrimination mechanisms often share common traits that make plausible to systematize them under valid categories for different legal systems.

Only by analyzing these mechanisms through categories will it be possible to form a complete idea about the state of Non-discrimination Law in a given legal system and therefore contribute to its development
} 
Palabras clave:

Discriminación; Mecanismos contra la discriminación; Derecho Antidiscriminatorio; derecho a la igualdad.

Key words:

Discrimination; Anti-discriminatory mechanisms; Non-discrimination Law; equality. 